\title{
A INTERLOCUÇÃO DO TERRITÓRIO NA AGENDA DAS POLÍTICAS SOCIAIS ${ }^{1}$
}

\author{
Dirce $K o g a^{2}$ \\ Vanice Aparecida Alves ${ }^{3}$
}

\section{RESUMO}

Este artigo tem como objetivo analisar as configurações socioterritoriais e suas interlocuções na agenda das políticas sociais, tendo como cenário a cidade de São Paulo, e como o (re)conhecimento dessa realidade tem se apresentado mais especificamente à Política de Assistência Social, na perspectiva de efetivação do acesso à proteção social da população em situação de vulnerabilidade social.

PALAVRAS-CHAVE: Território, Proteção Social, Políticas Sociais, Assistência Social

\section{INTRODUÇÃO}

Compreender as diferentes expressões da questão social brasileira tem se tornado, paradoxalmente, uma emergência rotineira, dada as multifacetadas imbricações contidas no processo de exclusão social. Também se mantém desafiadora a evidência de que tais expressões se dão no concreto dos territórios de vivência, nos mais de 5.560 municípios brasileiros, distintos nas suas dimensões populacionais, nas suas áreas geográficas e nas suas configurações econômicas, políticas, culturais e sociais.

\footnotetext{
${ }^{1} \mathrm{O}$ conteúdo deste texto foi originalmente elaborado pelas autoras para fins da IV Jornada Internacional de Políticas Públicas - JOINP, realizada no período de 25 a 28/08/2009, e consta dos Anais do evento sob o título "Território: lugar de desafios para a proteção social".

${ }^{2}$ Dirce Koga é assistente social, doutora em Serviço Social pela PUC/SP e professora do Programa de Mestrado em Políticas Sociais da Universidade Cruzeiro do Sul (São Paulo - SP).

${ }^{3}$ Vanice Alves é assistente social, mestranda em Políticas Sociais na Universidade Cruzeiro do Sul (São Paulo-SP).
} 
Destacaríamos as políticas de saúde e de assistência social no cenário atual de busca pela territorialização de respostas de proteção social por meio do SUS e do SUAS - Sistema Único de Assistência Social. Ambos sistemas trabalham com a perspectiva territorial no desenho de suas formas de intervenção junto aos cidadãos. Considerando o campo social tradicionalmente marcado pela determinação das ações a partir de "públicos-alvos", essa perspectiva traz novos elementos de análise.

É nesse contexto que surgem questionamentos quanto ao significado da territorialização, ou ainda a pertinência de se inserir na análise das expressões da questão social a dimensão territorial e sua interlocução com as políticas sociais. Nessa direção, o presente trabalho pretende pautar algumas evidências presentes na dinâmica de ocupação, formação e relações estabelecidas que colocam a dimensão territorial para além do espaço geográfico, tendo como cenário a cidade de São Paulo e a política de assistência social presente nesse cotidiano metropolitano.

Pretende-se analisar a Política de Assistência Social e sua relação com os territórios que compõem a cidade de São Paulo, no sentido de observar as desigualdades sociais que se dão no seu cotidiano e os desafios colocados para o enfrentamento das situações de vulnerabilidade social, por meio do acesso à proteção social dos atuais CRAS - Centros de Referência da Assistência Social.

Compreendemos que a questão socioterritorial se apresenta como um eixo central para buscarmos decifrar a complexidade da cidade de São Paulo e os desafios da proteção social nesse contexto. Dessa forma, este artigo debate sobre a importância da Política de Assistência Social se aproximar dessas configurações produzidas no âmbito do desenvolvimento capitalista, e como tem sido efetivado o SUAS, que preconiza a centralidade da vertente territorial e os múltiplos fatores que levam os indivíduos e os coletivos às situações de vulnerabilidade social. 


\section{TERRITÓRIO E PROTEÇÃO SOCIAL}

Para analisarmos a Política de Assistência Social na cidade de São Paulo e os impactos do modelo capitalista de regulação do(s) território(s), partimos da perspectiva de que o território se configura como um elemento relacional na dinâmica do cotidiano de vida das populações. E o fato do território estar tão presente no cotidiano e na vida das pessoas evidencia que a história não se faz fora do mesmo, mesmo porque não existe sociedade a-espacial.

Após a Constituição de 1988, São Paulo foi a primeira cidade a ter o direito de realizar o próprio tratamento intra-urbano. Abriu-se o debate público quanto à divisão territorial a adotar, permitindo que São Paulo obtivesse os resultados do Censo do IBGE de 1991 pelos 96 distritos $^{4}$ considerados a base oficial da cidade de São Paulo, referência para a sua gestão.

É interessante percebemos que apesar de ser a base oficial, segundo Nogueira (2009, p. 4) existem no país territórios que não tem definido seus limites, isso pelo fato da própria imprecisão das leis de criação de algumas cidades, o que conseqüentemente gera "disputas entre prefeituras por aeroporto, poço de petróleo, fábricas, recursos da União e até população”. Esta situação surgiu por conta dos preparativos para o Censo

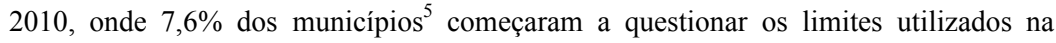
Contagem da População e o Censo Agropecuário em 2007. O autor assinala que tanto as prefeituras e o IBGE esclarecem que ambos não definem os limites territoriais e sim o Estado por meio dos órgãos estaduais de terras e cartografia.

\footnotetext{
${ }^{4}$ As 96 unidades territoriais são os denominados distritos que compõem na verdade o que consideramos a totalidade da cidade de São Paulo com atualmente 2.489 bairros, que segundo nossa compreensão devem ser compreendidos e interpretados no contexto histórico, sem perder as suas peculiaridades. ${ }^{5} 7,6 \%$ segundo o IBGE representam 425 prefeituras do país. 
As demandas pela localização das respostas sociais na cidade de São Paulo instalaram-se na gestão de 1989-1992 através de um conjunto de escritórios, delegacias e administrações locais, que segundo Sposati (2001) apresentavam-se de forma desarticulada das secretarias sociais que compunham a Prefeitura de São Paulo.

Assinala que essas iniciativas desenvolveram propostas desarticuladas entre si por não terem mecanismos que articulassem os "pedaços" ${ }^{\text {"6 }}$ da cidade, o que acabou enfraquecendo a dimensão territorial da cidade. No final da década de 80, e início de 90 as demandas aparecem com força, pois a população exigia: "a cidade da escola, do trabalho, da comida, do ônibus, da casa, da doença, da saúde, da educação, do analfabetismo, da produção e reprodução da vida diária. Lugares esses esquecidos pelo poder assentados nos pedaços centrais da cidade" (SPOSATI, 2001, p. 18).

Podemos perceber nesta conjuntura que os novos espaços da cidade que foram surgindo ao longo do tempo, não apresentavam a presença do Estado de forma articulada e efetiva, reproduzindo um modelo socioterritorial excludente. Um exemplo emblemático é o Jd. Piracuama $3^{7}$ com 16,5 mil m² de terreno, no qual em 2007 acabou sendo completamente ocupado, a ponto da área se unir a outras duas favelas que cercam o terreno (Jd. Piracuama 1 e Jd. Evana). Segundo Bedinelli (2008) os moradores não sabem explicar o fenômeno desse crescimento da favela, mas explicam que o processo de aquisição do terreno se deu por conta da demanda por terra.

Percebe-se que essas áreas são consideradas legítimas pelos moradores devido ao seu processo de apropriação, mas sabemos que na verdade são as áreas sobrantes, onde se concentram famílias em condições marcadamente de vulnerabilidade e exclusão social. Este modelo dominante de território(s) existentes na(s) cidade(s) do

\footnotetext{
${ }^{6}$ Metáfora utilizada pela autora Aldaíza Sposati para referir-se às diversas unidades de território(s) que compõem a cidade de São Paulo.

${ }^{7}$ Favela localizada na zona sul da cidade de São Paulo, em Campo Limpo.

Revista Serviço Social \& Saúde. UNICAMP Campinas, v. IX, n. 9, Jul. 2010
} 
país tem se tornado alvo da Política Pública de Assistência Social. Entretanto, é necessário ponderar que quando nos referimos aos dados estatísticos é evidente:

[...] que não se trata de esvaziar ou reduzir a importância dos cálculos estatísticos, dos indicadores socioeconômicos, mas de considerar suas potencialidades e limites de análise. Faz-se necessário associar aos números outros olhares sobre os territórios capazes de compreender as conexões, desconexões, interações e fraturas que compõem sua dinâmica relacional (KOGA, 2008, p. 3).

Diante deste contexto podemos supor que este modelo dominante configurouse nas primeiras divisões socioterritoriais da cidade, conforme Sposati (2001) ao longo das primeiras décadas do século XIX as terras da cidade foram recebendo destinos públicos como hospícios, cadeias, cemitérios etc. E com o crescimento da população de São Paulo do século XVIII, do XIX e a São Paulo urbana do século XX, demonstram que este crescimento populacional não acompanhou o trato com a cidade em todos os seus territórios.

Nesse sentido, apontamos duas questões da vivência urbana que está atingindo os diversos territórios das metrópoles: as favelas, e do mundo: a fome. Conforme Carolyn Steel (2008) ${ }^{8}$ a questão da fome é causada pela evolução das cidades e da agricultura industrial que alterou a relação do homem e a natureza, no sentido de que com os avanços tecnológicos e dos transportes, fez com que os alimentos deixassem de ser produzidos próximos das cidades, podendo vir de qualquer lugar do mundo; denomina essa desconexão de "era não-geográfica" da alimentação, e considera que essa expansão tenha se dado nas últimas décadas, e que a solução seria retornarmos a

\footnotetext{
${ }^{8}$ Arquiteta que passou estudando o assunto "fome" nas últimas décadas, e é autora do recém-lançado livro "Hungry City - How Food Shapes Our Lives". Ed. Chatto \& Windus. Traduzindo "Cidade com Fome - Como a Comida Define Nossas Vidas".

Revista Serviço Social \& Saúde. UNICAMP Campinas, v. IX, n. 9, Jul. 2010
} 
regionalização da produção de alimentos, respeitando as estações do ano e as características dos países. Considera esse início como a "era neo-geográfica", em que a geografia retoma a sua importância. Percebemos então que o modo como as cidades vão crescendo, organizando, produzindo e (re)distribuindo sua riqueza ao longo da história pode dizer muito sobre as configurações dos espaços e o quanto à lógica de mercado implica neste processo.

Com relação às favelas e as configurações dos espaços, podemos apontá-las como vivência urbana complexa, apresentando-se na cidade de São Paulo especificamente nas áreas urbanas denominadas vulneráveis, por ser considerados espaços de não-interferência para o capital, pois não traz ganho imobiliário. E que segundo Rolnik (2008, p.10) esta população excluída da regularidade produziu a "cidade fora da cidade".

Conforme o Mapa de Vulnerabilidade Social, a vulnerabilidade está associada não apenas as características socioeconômicas, mas está associada a outros diversos fatores (baixos níveis de escolaridade, acesso a serviços públicos, perfis familiares), como também características demográficas dos grupos sociais, dos setores censitários, aspectos que colocam ou podem colocar as pessoas em situações de risco (agravos à saúde, gravidez precoce e jovens vítimas de homicídio, entre outros).

Neste contexto de múltiplos fatores podemos assinalar que as características socioterritoriais das áreas vulneráveis demonstram ainda à distância entre o acesso da população às políticas públicas e do Estado, ao mesmo tempo em que essas características demonstram também quais as prioridades do território para enfrentar as situações de vulnerabilidade. 
Haja vista, por exemplo, a implementação do Programa Bolsa Família ${ }^{9}$ que ao construir o conhecimento dos diversos territórios que compõem o nosso país, identificou quais as relações que permeavam as demandas coletivas os territórios vulneráveis, ou seja, traduziu o território a partir da vivência das famílias "pobres" focalizando e cobrindo, as áreas vulneráveis com famílias que encontram-se abaixo da linha da pobreza. Isso significa dizer, que a relação do território e seus sujeitos sociais demonstram que não bastam apenas os dados e as características, mas como estão exercendo a vida no território.

Ainda com relação às situações de vulnerabilidade e suas configurações podemos citar Bedinelli (2008) que em seu levantamento aponta que o crescimento populacional nas favelas foi $660 \%$ maior em São Paulo entre 2000 e 2007, mas aponta também que a área total que as favelas ocupam na cidade caiu - em 2003 a área era de $28 \mathrm{~km}^{2}$ contra $23 \mathrm{~km}^{2}$ em 2007 -, e isso se deve ao fato das favelas não ter mais espaço para construir ${ }^{10}$, então a estratégia utilizada pela população está sendo a construção vertical das casas, retratando talvez um novo fenômeno nas configurações e dinâmicas socioterritoriais que é a verticalização das favelas. Para Suzana Pasternak (2008) isso acarretou um aumento preocupante com relação à densidade demográfica dessas áreas, pois o fato das casas estarem muito próximas uma das outras faz com que a circulação de ar não seja eficaz, considerando ser um adensamento forte para doenças contagiosas.

Esta identificação que hoje conhecemos, de localização de determinada área de vulnerabilidade como as favelas e seus respectivos distritos, foi construída por um

\footnotetext{
${ }^{9}$ Para saber, mais sobre a questão da cobertura do programa no país recomendamos a "Radiografia do Bolsa Família” (Revista Época, 2008, p. 76-7)

${ }^{10}$ Segundo Bedinelli (2008) os urbanistas denominam este fenômeno de "adensamento urbano", ou seja, não existe mais espaço para construir, porém a população continua crescendo. Outro fenômeno apresentado é que nos últimos 21 anos as favelas estão desaparecendo e não aparecendo novas ocupações, por conta da escassez de terrenos vagos.

Revista Serviço Social \& Saúde. UNICAMP Campinas, v. IX, n. 9, Jul. 2010
} 
processo de transformações da forma como a população foi "ocupando" os espaços e como o poder público foi compreendendo-os e respondendo.

Em 1991, segundo Sposati (2001) a cidade de São Paulo tinha 48 subdistritos e 10 distritos num total de 56 agregações territoriais, sendo que foi após a Constituição de 1988 e por meio de múltiplas discussões com especialistas do IBGE, Sabesp, Eletropaulo, Correios, secretarias municipais e estaduais, representantes comunitários e dirigentes de serviços públicos entre outros, que esse conjunto recebeu novo tratamento em 1990 desencadeados pela Secretaria das Administrações Regionais e com apoio da Câmara Municipal. São Paulo agregou-se aos 96 distritos citado anteriormente, sendo extinta a categoria subdistritos, consolidado pela lei 10.932 de 15/1/91 e alterada lei municipal 11.220 de 20/5/92.

Em janeiro de 2001 a cidade de São Paulo contava com 28 administrações regionais, que segundo Sposati (2001), precisava ainda de uma proposta que atendesse os artigos 77 e 78 da Lei Orgânica do Município que exigia implantar as chamadas subprefeituras como forma de governo da cidade, como também os Conselhos de Representantes Regionais exigidos pelos artigos 55 e 57 da Lei Orgânica do Município. A partir dessa trajetória de organização territorial da cidade é possível apontar que a cidade durante a sua história estava buscando inserir nos territórios da cidade a idéia do poder público, enquanto uma maneira da cidade se compreender como cidade, no sentido de reconhecer seus territórios.

Em contraposição, no momento atual, temos o desafio da implantação da Política de Assistência Social onde o poder público através dos CRAS tem que se fazer presente nos territórios, principalmente nos vulneráveis. Tem sido comum nas cidades brasileiras, o espaço urbano ser compreendido e divido de maneira diversa entre os órgãos públicos, o que termina por gerar uma fragmentação das políticas públicas. 
Conforme Milton Santos (2007) o território é mais do que qualquer outra instância da sociedade. Nos territórios de vulnerabilidade social podemos observar ainda os limites de mobilidade, quando o cidadão não consegue nem circular no seu território e nem no território chamado "cidade de São Paulo". Isso significa também apontar que a cidade de São Paulo, apesar de ser uma metrópole, possui dois contrastes marcantes; de um lado a concentração de tecnologia, capital e produção, e de outro lado se assiste a perversidade que imobiliza seus cidadãos de circular, deixando-os na exclusão social de seus territórios vulneráveis e com a ausência ou frágil presença do poder público nesses lugares.

Nessa perspectiva é que se insere o território como um elemento essencial para se pensar a efetivação do acesso à proteção social básica e especial, por meio dos serviços socioassistenciais, como por exemplo, os CRAS $^{11}$ nos territórios, possibilitando a proximidade do poder público nesses lugares, ou seja, é o reconhecimento do território enquanto: vida, por isso necessita de proteção para a sua existência.

A partir de 2004 com a aprovação da Política Nacional de Assistência Social - PNAS - em 2005 e com a regulação do Sistema Único de Assistência Social - SUAS -, houve a (re)definição das regulações. Ambas trouxeram avanços e reafirmaram os princípios e diretrizes da LOAS, e segundo o MDS (2007) isso exigiu redefinições teóricas na assistência social com ênfase na matricialidade familiar, na dimensão socioterritorial, nos serviços socioassistenciais e nos modos de estruturação hierarquizada da proteção básica e especial. ${ }^{12}$

\footnotetext{
${ }^{11}$ Conforme a PNAS (Política Nacional de Assistência Social) considerado uma unidade estatal, de base territorial, que executa serviços de proteção social básica (BRASIL, 2004, p. 35).

${ }^{12}$ A proteção básica e especial se faz através da atenção diferenciada de acordo com a complexidade (alta e média), com objetivo de atender as necessidades sociais, rompendo com a lógica da atenção às carências dos "necessitados" (BRASIL, 2007). 
Segundo o MDS (2007) o fato das necessidades adentrarem os serviços de proteção social do CRAS por estarem inseridos nos territórios de extrema vulnerabilidade, faz com que haja uma ampliação das demandas, o que exige um maior investimento material e de recursos humanos. Compreendemos que além deste investimento seja necessário também pensarmos formas de gestão que consiga dar conta das complexas configurações da(s) cidade(s) incluindo as metrópoles como São Paulo. Temos que pensar formas criativas para os diversos territórios, na totalidade de São Paulo, por exemplo, os territórios da zona leste têm sua peculiaridade com relação aos demais e vice e versa. Portanto estar no território é além de uma estrutura física, significa muito mais do que um espaço geográfico, é a mobilidade do CRAS enquanto efetivação do acesso a proteção social.

\section{CONCLUSÃO}

O artigo buscou analisar a Política de Assistência Social na perspectiva de compreender o território e suas dinâmicas, quando não se trata apenas de dividi-lo geograficamente para poder geri-lo. Nesse contexto, por meio do CRAS, o poder público pode se fazer presente nos territórios considerados vulneráveis, ganhando sentido nas vidas da população.

A análise possibilita apontar os avanços com os CRAS na questão socioterritorial, como também compreender as relações estabelecidas da própria Política de Assistência Social nos e entre os territórios das cidades brasileiras. Pois, os territórios apenas podem ser considerados como tal, quando pensados junto com a população, a partir do seu uso, como já ensinava Milton Santos ao dizer: “O território em si, para mim, não é um conceito. Ele só se torna um conceito utilizável para a análise social 
quando o consideramos a partir do seu uso, a partir do momento em que o pensamos juntamente com aqueles atores que dele se utilizam" (SANTOS, 2000, p. 22).

Nesse sentido, apontamos como desafios a construção de uma rede efetiva de proteção social por meio dos CRAS que esteja no território e com o território, enquanto uma presença do Estado que vai além da função equipamentista, pois se constitui em mais um ator social no cotidiano da dinâmica de vida da população. Dessa forma, se configura o desafio de tornar o Sistema de Proteção Social Básica e Especial acessível à cidade e aos cidadãos, ou seja, a proteção no sentido também da garantia da mobilidade dos cidadãos no(s) território(s) e no acesso aos serviços públicos, onde o sentido da proximidade não se restrinja à distância física, mas, essencialmente, de acessibilidade com qualidade.

\section{ABSTRACT}

This article aims to analyze settings social and territorial and their interlocutors in agenda of social policies, having as scene the city of São Paulo, and as the (re) aware of this reality has appeared more specifically to the policy on social assistance, in the perspective of effective access to social protection of population in situations of social vulnerability.

KEYWORDS: Territory, Social Protection, Social Policy, Social Assistance

\section{REFERÊNCIAS BIBLIOGRÁFICAS}

BRASIL, Ministério do Desenvolvimento Social e Combate à Fome - MDS. Política Nacional de Assistência Social - PNAS. Brasília - DF: 2004. p. 9-59. Ministério do Desenvolvimento Social e Combate à Fome - MDS. SUAS: configurando os eixos da mudança. Brasília DF: Caderno 2, nº 2, Ano 2, mar. 2007. 
CENTRO DE ESTUdOS DA METRÓPOLE - CEM. Mapa da vulnerabilidade

Social da população da cidade de São Paulo. Centro Brasileiro de Análise e Planejamento - Cebrap/SESC. São Paulo: Secretaria Municipal de Assistência Social de São Paulo SAS - PMSP. 2004.

KOGA. D. A dimensão territorial no processo de construção do conhecimento e da realidade social nas áreas mais vulneráveis da metrópole. Secretaria Municipal Adjunta de Assistência Social - Prefeitura de Belo Horizonte. Belo Horizonte. 2008.

KOGA, D., ALVES, V. Território: lugar de desafios para a proteção social. São Luis MA, Anais da IV Jornada Internacional de Políticas Públicas, 25 a 28/08/2009.

SANTOS, M. Território e sociedade entrevista com Milton Santos. São Paulo: Fundação Perseu Abramo, $2^{\mathrm{a}}$ ed., $3^{\circ}$ reimp. 2007.

. Espaço e Sociedade: ensaios. Petrópolis, RJ: Vozes, 1979.

SPOSATI, A, TOLEDO, J.R. de (org.). Cidades em Pedaços. São Paulo: Brasiliense, 2001.

\section{ARTIGOS DA IMPRENSA}

BEDINELLI, T. Saturadas, favelas se verticalizam em SP. Folha de São Paulo, São Paulo, 14 jul. 2008. Folha Cotidiano, Caderno C1.

'Boom' faz mais nova favela de SP crescer. Folha de São Paulo. São

Paulo,14 jul.2008. Folha Cotidiano.Caderno C3.

BOLSA FAMÍLIA: as conquistas e os limites do programa. São Paulo. 10 nov. 2008. Época Debate. Revista Época. No ${ }^{\circ}$. 547. Editora Globo, p. 70-86.

STEEL. C. Geografia da Fome. Folha de São Paulo. São Paulo. 6 jul. 2008. Caderno Mais, p. 4. 
NOGUEIRA, Í. Mais de 400 cidades disputam territórios com seus vizinhos. Folha de São Paulo. São Paulo. 2 fev. 2009. Folha Cotidiano. Caderno C 4. 